\title{
Mulheres: perspectivas e desafios em relação à água
}

DOSSIER ÁGUA E MULHER

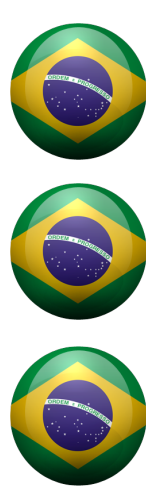

\section{Ethel Martinez de Azevedo Camargo}

Assessora Jurídica do Ministério Público Federal; Especialista em Direito Público pela Universidade do Sul de Santa Catarina; Bacharel em Direito pela Universidade Presbiteriana Mackenzie. São Paulo [SP] Brasil. $<$ ethel@mpf.mp.br>

\section{Margarida Yassuda}

Vice-Presidente Women for Water Partnership; Diretora Primeira Secretária da Federação das Associações de Mulheres de Negócios e Profissionais-BPW Brasil; Delegada da BPW junto a ONU na Conferência CSW 59, BPW Leadership Summit em Nova York. São Paulo [SP] Brasil. <vicepresident-sc@womenforwater.org>

\section{Sandra Akemi Shimada Kishi}

Procuradora Regional da República; Gerente do Projeto Conexão Água 4⿳ạ-CR/MPF; Coordenadora Adjunta do Fórum Nacional de Recursos Hídricos do Conselho Nacional do Ministério Público; Mestre em Direito Ambiental; Professora de Direito Ambiental (Unimep). Piracicaba [SP] Brasil. <sandrakishi@mpf.mp.br>

\section{Resumo}

O presente artigo traz conclusões e impressões acerca da sessão Mulheres, Perspectivas e Desafios, promovida pela Woman for Water Partnership, durante o Fórum Mundial da Água, em Brasília, de 19 a 23 de março de 2018. 0 artigo também tem por objetivo descrever algumas das atividades desenvolvidas pelo Projeto Conexão Água (da 4⿳a aâmara de Coordenação e Revisão do Ministério Público Federal) por ocasião do Fórum, com profícuas participações de colaboradores e membros da Comissão Consultiva do Projeto Conexão Água do MPF, destacando-se no presente trabalho as participações de mulheres, líderes, em situação de vulnerabilidade ou não, para em conjunto valorizarem o importante papel de mulheres na efetividade da inclusão social e da preservação dos recursos naturais, em especial, a água.

\section{Palavras-chave}

Mulheres. 8º Fórum Mundial da Água. Liderança feminina. Participação feminina. Gestão hídrica.

\section{Women: perspectives and challenges in relation to water}

\begin{abstract}
This article presents conclusions and impressions about the panel Women Perspectives and Challenges, promoted by Woman for Water Partnership, during the World Water Forum in Brasilia, March 19-23, 2018. The article also aims to describe some of the activities developed by the Water Connection Project (from the 4th Chamber of Coordination and Review of the Federal Public Prosecution Service) on the occasion of the Forum, with participation of collaborators and members of the Projeto Conexão Água do MPF, highlighting in the present work the participation of women leaders, in a situation of vulnerability or not, to jointly value the important role of women in the effectiveness of social inclusion and preservation of natural resources, especially water.
\end{abstract}

\section{Keywords}

Women. 8th World Water Forum. Women's leadership. Female participation. Water management. 


\section{Introdução}

Somente o envolvimento de homens e mulheres em iniciativas integradas conduzirá a humanidade à boa governança dos recursos naturais e, em última instância, à sustentabilidade da espécie humana na Terra.

As vulnerabilidades sociais em tempos de crise intensificam o perigo e contribuem para a concretização dos riscos ecológicos, exigindo, assim, instrumentos de controle de risco mais rigorosos. Territórios com imenso risco de devastação ou degradação ambiental, propensas a desastres ecológicos, exigem uma tutela mais protetiva do ambiente e da sadia qualidade de vida, especialmente na hodierna sociedade de risco e frente aos grandes desastres ambientais que têm nos acometido.

Diante desse quadro, promover o acesso equitativo à água passa por empoderar as mulheres em todo o mundo.

A integração das mulheres na gestão ambiental já foi reconhecida em inúmeros documentos internacionais, dentre os quais se destaca o preâmbulo da Convenção sobre Diversidade Biológica, integrada ao ordenamento jurídico brasileiro pelo Decreto Presidencial n. 2.519/98, que menciona expressamente o papel fundamental da mulher na conservação e na utilização sustentável da diversidade biológica, afirmando a necessidade da plena participação da mulher em todos os níveis de formulação e execução de políticas para a conservação da diversidade biológica.

Na prática, entretanto, mulheres e homens geralmente têm papéis muito diferentes nas atividades que envolvem abastecimento e saneamento. Na zona rural, enquanto os homens envolvem-se mais no manejo das águas para irrigação e pecuária, as mulheres frequentemente são as maiores provedoras e gerenciadoras da água de uso doméstico, zelando pela higiene nos lares. Devido a esse papel nas comunidades mais humildes, as mulheres geralmente detêm conhecimentos sobre os recursos hídricos locais, sua qualidade e confiabilidade. No entanto, quando se trata de decisões públicas, os homens geralmente detêm as posições de poder sobre os recursos hídricos.

A melhoria da infraestrutura de abastecimento e saneamento básico exonera as mulheres da coleta de água em poços distantes para prover as necessidades da família, liberando-as para atividades geradoras de renda e frequência escolar. Contudo, embora as mulheres sejam frequentemente as maiores usuárias diretas, as decisões para o gerenciamento público de recursos hídricos fica em sua maioria restrita aos homens. Nesse ponto, a situação das mulheres remete ao conceito de grupos vulneráveis, considerados como tais aqueles que não tenham força suficiente a se fazer ouvir ou se fazer reconhecer e que devem ser incluídos no diálogo ao longo de todas as fases dos processos decisórios ambientais.

É por isso que a Declaração de Dublim sobre Água e Desenvolvimento Sustentável de 1992, da qual o Brasil é signatário, assume em seu Princípio no 3 que as mulheres têm papel central no fornecimento, gestão e proteção da água. Em muitas sociedades a influência das mulheres na tomada de decisões concernentes à água é bastante limitada, muito embora elas sejam as responsáveis pela captação desse valioso e indispensável recurso no cotidiano de suas comunidades.

Por outro lado, impõe-se não apenas ao Estado, mas a toda coletividade, o dever de facilitar os meios para tal transformação social, numa gestão integrada e participativa para o seu desenvolvimento.

Nesse sentido, a organização Women for Water Partnership vem contribuindo desde 2004 em projetos de acesso equitativo à água e desenvolvimento sustentável, com especial atenção à inclusão das mulheres nos processos decisórios de governança da água. 0 desenvolvimento de capacidades tanto de instituições como de indivíduos é um aspecto indispensável de todos os projetos apoiados pelo Women for Water Partnership1.

1 Disponível em: <https://www.womenforwater.org/who-we-are.html> 
No contexto do 8º Fórum Mundial da Água, realizado de 18 a 23 de março de 2018 em Brasília [DF], a organização Women for Water Partnership promoveu a sessão Mulheres: Perspectivas e Desafios, na qual foram debatidos os desafios e as tendências em relação à participação das mulheres na governança da água e apresentadas diretrizes e recomendações, visando a maiores conquistas das mulheres nessa área em nível global. Com a mesma intenção de valorizar o empoderamento de mulheres e minoriais, dando-lhes vozes em espaços de reflexões e debates sobre temas atuais e desafiantes na questão hídrica, o Projeto Conexão Água que desenvolve parceria com a organização Women for Water Partnership coordenou na semana do 8o Fórum Mundial da Água em março de 2018, em Brasilía [DF], diversos painéis em diferentes sessões, dentre os quais: a mesa redonda "Água: desafios e soluções por uma diversidade de olhares" de rodada de entrevistas e debates na Escola Superior do Ministério Público da União, gravações de vídeoaulas, coordenação do painel "Monitoramento Social da Qualidade da Água nas áreas rurais e periurbanas" e da sessão "Crimes Ambientais, Justiça, Compensação e Violação de Direitos", com contribuições valorosas de mulheres em defesa da água, em palestras, relatorias e coordenações de trabalhos.

\section{Desafios e tendências}

A sessão apresentou os grandes desafios mundiais em relação à água, tais como: superar a escassez, garantir qualidade de água para todos, assegurar segurança alimentar. Todas essas questões são diretamente relacionadas com a falta de acesso e controle dos recursos hídricos pelas mulheres.

A vasta gama de desafios enfrentados pelas mulheres abrangem tanto dificuldades causadas pela distância dos locais de coleta de água, falta de banheiros e qualidade da água - situações salientadas por Asha Abdulrahman, parceira do Women For Water Partnership no Quênia - como a falta de inserção das mulheres nos espaços decisórios, conforme salientado pelas participantes brasileiras.

Em relação ao Brasil, no segmento de recursos hídricos geralmente as mulheres atuam no quadro técnico e, apesar de crescente mobilização e inserção no mercado de trabalho, há grande dificuldade de acesso a cargos de decisão. Na gestão pública, através de concursos públicos as mulheres têm ingressado em áreas tradicionalmente dominadas pelos homens de forma mais equilibrada. No setor hídrico, contudo, assumem a função de dar suporte técnico, trazer conhecimento, experiência e subsídios para os "tomadores de decisão", mas ainda apenas influenciam, não decidem as questões estratégicas de gestão de recursos hídricos.

Os desafios são grandes, pois envolvem uma significativa mudança cultural sobre o papel da mulher na sociedade e na gestão da água. À mulher não incumbe apenas o papel de quem organiza, administra e dá suporte técnico e operacional para que as coisas aconteçam, mas também o papel de agente decisório, com poder para inserir, no centro das discussões e decisões, questões relevantes para as mulheres que são a maioria dos usuários e principais consumidoras com poder de influenciar quanto à qualidade, disponibilidade e regulamentação de seu fornecimento. A superação deste desafio envolverá ações de educação, capacitação, conscientização, articulação e mobilização. Uma transformação fundamental é necessária, exigindo ação em todos os níveis.

\section{Boas Práticas, Projetos e Ações}

No âmbito nacional, ressaltou-se o estabelecimento do Comitê Pró-Equidade de Gênero da Agência Nacional de Águas em 2017, com grande relevância no papel da agência para criação de uma estrutura institucional e de apoio para a gestão inclusiva, conforme compromisso assumido pelo Brasil para implementar o Princípio no 3 da Declaração de Dublin.

Do Quênia, o Projeto de Coleta de Água de Chuva ilustrou a luta do Mwihoko Women Group, que transformou um projeto inicialmente fracassado em uma história de sucesso, levando água e saneamento a uma comunidade carente, permitindo o seu desenvolvimento econômico. Aumentou o acesso à água potável em 80 domicílios, beneficiando 480 pessoas e 2040 crianças em idade escolar com água potável e melhores condições de saneamento, instalação de banheiros e chuveiros 
ecológicos. Aliviou o fardo daqueles que precisavam caminhar longas distâncias para buscar água, liberando tempo para o desenvolvimento econômico das famílias e da comunidade. Através desse projeto observou-se a conscientização, transparência, governança, liderança, empoderamento e desenvolvimento econômico. 0 objetivo no 4 da Agenda 2030 da ONU para o desenvolvimento sustentável - que se traduz em assegurar a educação inclusiva e equitativa e de qualidade, e promover oportunidades de aprendizagem ao longo da vida para todos - foi pressuposto para o sucesso das mulheres Mwihoko. A pobreza não terminou para todos, mas os resultados já alcançados indicam que foram lançadas as bases para mais progressos.

De Myanmar, a demonstração da necessidade dos governos trabalharem com os atores da sociedade civil. Em uma democracia florescente, isso nem sempre é fácil, uma vez que os papéis e responsabilidades dos atores não-estatais não estão claramente definidos e compreendidos. Quanto ao engajamento de mulheres na tomada de decisões nos níveis locais de acordo com o Princípio de Dublim 3, a ONG Water Mothers of Myanmar posiciona-se como intermediária para preencher as lacunas existentes na interlocução entre governo e sociedade civil para elaboração de políticas de recursos hídricos. Por um lado, incentiva e apoia os grupos de mulheres locais a agir em suas próprias comunidades; por outro, conscientiza os tomadores de decisão sobre a importância de trabalhar e apoiar os grupos de mulheres e outros atores não estatais. É um processo contínuo e gradual de transformação.

Da Nova Zelândia, a cultura maori trata os recursos hídricos de maneira holística, demonstrando a conexão pessoal com a fonte da vida. Nesse contexto, as mulheres são protetoras, possuem tendência para a preservação e a paz, olhar que é necessário também para a gestão hídrica.

Certamente tais objetivos ajudarão na concretização do Direito Humano à Água e ao saneamento, que passa por sua disponibilidade de maneira contínua, suficiente, segura, com qualidade aceitável, utilização de instalações fisicamente acessíveis e preços razoáveis para todos, com regras e mecanismos para a integral inclusão dos mais vulneráveis. Reconhece-se, cada vez mais, a necessidade de que as comunidades e grupos vulneráveis, como as mulheres, sejam capacitados para participarem dos processos decisórios sobre o uso da água, dotado de uma visão transdisciplinar, aberta e inclusiva, capaz de valorizar o conhecimento desses grupos vulneráveis.

Todos esses matizes e visões de proteção têm ampla consonância com as prioridades da atuação do Ministério Público Brasileiro no tocante às questões hídricas, conforme a Declaração do Ministério Público sobre os Direitos da Água, que traz 10 princípios, discutidos e apresentados formalmente por ocasião do Fórum Mundial da Água, conforme o link: [...] [...] <http://www.mpf.mp.br/pgr/documentos/Declaracao_do_Ministerio_Publico.pdf>.

Na esteira da modernização das instituições jurídicas inaugurada pela Emenda Constitucional n. 45, o Conselho Nacional do Ministério Público tem buscado formas alternativas de atuação proativa, dos membros do Ministério Público, com vistas à efetividade na resolução de questões candentes da sociedade.

Nessa linha de planejamento estratégico de inovadoras formas de atuação proativa de membros do Ministério Público Brasileiro, nasceram os Projetos Qualidade da Água e Conexão de Água, os quais valorizam um controle social dos riscos socioambientais, por meio de ferramentas de monitoramento social da água e pela articulação de gestores públicos e privados e representantes de diversos setores, públicos e privados, da sociedade civil, academia, ONGs e setor empresarial.

As atuações institucionais planejadas estratégica e conjuntamente por membros do Ministério Público Brasileiro e as metodologias construídas em governança colaborativa são objeto do Manual de Atuação para "Efetivação das Metas de Qualidade das Águas no Brasil: Atuação Estratégica para a Melhoria da Qualidade das Águas". O manual é produto do Projeto Qualidade de Água (2015-2017) e do Projeto Conexão Água (2017-2019) que consolida as contribuições dos referidos projetos, visando à melhoria da qualidade e quantidade das águas no país e da governança da água, servindo de apoio à atuação do Ministério Público, em prol da sociedade.

Contribuiu para o surgimento dos Projetos, especialmente na Região Sudeste, o cenário de crise hídrica cujo ápice deu-se entre os anos de 2013 a 2015. Nesta oportunidade, ficou patente a 
necessidade de maior articulação interinstitucional, para efetiva implantação dos instrumentos de política de recursos hídricos, saneamento ambiental e saúde, bem como a necessidade de facilitação de acesso a informações sobre águas e monitoramento de qualidade em sistemas integrados para um controle social.

Referido Manual de Atuação para "Efetivação das Metas de Qualidade das Águas no Brasil: Atuação Estratégica para a Melhoria da Qualidade das Águas" e seus "Guias e Sugestões de Atuação Participativa e Articulada" promovem estratégias de aproximação dos conhecimentos técnicos e legais, de multiáreas e multiníveis, para a implementação de boas práticas na gestão da água, incluindo estratégias para a efetivação das metas de qualidade e metodologia de articulação entre os instrumentos de gestão e planejamento com transparência e empoderamento de vulnerabilidades, contribuindo de forma efetiva com a reversão do cenário de degradação das águas e na transformação de desafios de gestão em oportunidades. Eis o link para o Manual: [...] [...] <http://conexaoagua.mpf.mp.br/arquivos/manuais/2018-05-efetivacao-das-de-qualidadedas-aguas-no-brasil.pdf $>$.

Destaca-se o Portal digital do Projeto Conexão Água também como uma importante ferramenta, já que abriga espaço virtual que permite o acesso livre a dados e informações sobre monitoramento da água oriundos de diversos órgãos de controle e de gestão em recursos hídricos, meio ambiente, energia e saúde ambiental: <http://conexaoagua.mpf.mp.br/>.

Visando a um melhor entendimento sobre as várias frentes de atividades e produtos do Projeto Conexão Água, há um artigo publicado na revista no 1 do Conselho Nacional do Ministério Público - CNMP, em 8.08.2017, sobre os Projetos Qualidade da Água e Conexão Água (aprovado pela Procuradoria Geral da República/ MPF Portaria no 40, de 19 de janeiro de 2015) e Conexão Âgua (aprovado em maio de 2018, sem ressalvas e em grau de prioridade pelo Escritório de projetos do MPF/PGR). A versão eletrônica do artigo é encontrável no link para a revista do CNMP. Tratase do artigo "Ministério Público Resolutivo: Projeto Qualidade da Água e Projeto Conexão Água", disponível no seguinte link: <http://www.cnmp.mp.br/portal/todas-as-noticias/10613-lancadaprimeira-edicao-de-revista-sobre-sustentabilidade-no-cnmp>.

O Projeto Conexão Água, em parceria com o Women for Water Partnership, valoriza a governança como exercício da participação e do controle social, com inclusão de grupos vulneráveis, como as mulheres, na planificação e nos processos decisórios em matéria de recursos hídricos e socioambientais, nivelando capacidades e forças, proporcionalmente às inerentes vulnerabilidades associadas ao gênero. Com essa preocupação, membros e colaboradores da Comissão Consultiva do Projeto Conexão trabalharam como coordenadores, relatores e palestrantes em várias sessões do 8o Fórum Mundial da Água, tais como: a mesa redonda de entrevista e debates na Escola Superior do Ministério Público da União, com a participação da Presidente da Women for Water Partnership e da Soroptimist da Holanda, Mariet Verhoef-Cohen e a gravação de videoaula com a Profa Lia Vasconcelos Professora da Faculdade de Ciências e Tecnologia da Universidade Nova de Lisboa em Portugal; o painel "Monitoramento Social da Qualidade da Água nas áreas rurais e periurbanas" e a sessão "Crimes Ambientais, Justiça, Compensação e Violação de Direitos", respectivamente, na Seção Especial e no Processo Cidadão, que valorizaram e contaram com participações de mulheres líderes, e representantes de comunidades tradicionais e do $3^{\circ}$ setor (mulheres indígenas, de comunidade ribeirinha e de ONGs) que expuseram situações de vulnerabilidades, resiliências e desafios.

A Agenda 2030 para o Desenvolvimento Sustentável proclama, dentre seus objetivos, um "engajamento e parceria de toda a sociedade" para uma governança da água e um desenvolvimento equitativo em harmonia com a natureza. No domínio público da água, a abordagem participativa e multipartidária em diferentes níveis já está ancorada na Declaração da Conferência das Nações Unidas Eco/1992, avaliando a participação (princípio 10), o princípio da precaução (princípio 15 ) e do poluidor-pagador com internacionalização dos custos ambientais (princípio 16). 0 nivelamento de forças e de oportunidades e a capacitação de grupos vulneráveis são pressupostos para a efetividade desses direitos. 


\section{Vozes de mulheres nos processos decisórios ambientais e sobre águas: diretrizes normativas e recomendações}

As conquistas das mulheres ao longo dos anos — do direito ao voto, educação, trabalho e salário igual e a luta para participação plena e isonômica em todas as esferas da sociedade - podem ser conectadas ao Princípio no 3 da Declaração de Dublin, que consiste em criar as condições prévias para que as mulheres tenham um papel central na provisão, gestão e salvaguarda da água, inclusive na tomada de decisões em formas definidas por elas.

A participação da Procuradora-Geral da República, Raquel Elias Ferreira Dodge, na sessão "Mulheres Perspectivas e Desafios" valorizou a base legal dos direitos humanos à água e ao saneamento, que não apenas estipulam o direito de ter acesso adequado a esses recursos, mas também o direito à participação na modelagem da provisão, gestão e salvaguarda da água de forma sustentável.

Portanto, é um processo oportuno e urgente a transformação da sociedade para a definitiva inclusão das mulheres nos processos decisórios que assegurarão a segurança hídrica para todos. A efetivação deste princípio - que foi acordado há mais de 25 anos, mas ainda carece de impulso em muitas partes do mundo - deve ser um esforço comum e contínuo de homens e mulheres.

A implementação do Princípio no 3 requer políticas positivas para atender às necessidades específicas das mulheres, para equipá-las e capacitá-las a participarem em todos os níveis dos programas de recursos hídricos, incluindo a tomada de decisões, terem o papel de agentes de mudanças em nível local e internacional.

Criar oportunidades para as mulheres passa por ações governamentais que fomentem a participação. Nesse sentido, a criação de agendas propositivas pode ter um impacto que viabilize programas estatais efetivos nessa área, evitando investimentos mal planejados e que onerem excessivamente os cofres públicos. 0 objetivo é a atuação das mulheres em todos os níveis e fases de decisão envolvidas na gestão hídrica.

Com efeito, sobre participação pode-se fazer uma analogia com o artigo 216-A da Constituição da República Federativa do Brasil, na dicção incluída pela Emenda Constitucional no 71, de 2012. 0 dispositivo constitucional prescreve o sistema nacional de cultura, em regime de colaboração, de forma descentralizada e participativa, institui um processo de gestão e promoção conjunta de políticas públicas de cultura, democráticas e permanentes, pactuadas entre os entes da Federação e a sociedade, tendo por objetivo promover o desenvolvimento humano, social e econômico com pleno exercício dos direitos culturais. $\mathrm{O}$ inciso X do artigo 216-A consagra em nível constitucional a democratização dos processos decisórios com participação e controle social. De fato, a regra do controle social constitui um verdadeiro direito fundamental, que se aplica a todos, sem distinção de gênero, não distinguindo homens de mulheres.

Em matéria de recursos hídricos e saneamento, o controle social por toda a coletividade pressupõe o acesso à informação adequada. Sem o acesso à informação hídrica não haverá participação e tampouco o devido controle social (artigos $2^{\circ}$ e $3^{\circ}$ da Lei de Política Nacional de Saneamento Básico). 0 princípio do controle social - somado ao princípio da participação - caracteriza uma efetiva governança - através da efetiva participação em todas as fases dos atos decisórios.

A gestão de riscos socioambientais tem abrigo em comandos constitucionais e legais sobre o princípio da precaução (art. 225, caput e parágrafo 1ํㅡ, IV da CF/1988), do controle do risco (artigo 225, V e VII, da CF/1988) e do controle social (artigo 216-A, inciso X, CF/1988 c.c. artigo 3ㅜ, VI da Lei de Política Nacional de Resíduos Sólidos e artigo 3o, IV, da Lei de Política Nacional de Saneamento Básico) que devem ser conjugados de forma sistematizada.

Assim, para a efetividade do direito à participação e ao controle social, os indivíduos em uma comunidade precisam estar capacitados para agir e decidir com liberdade, de forma isonômica, de forma compensatória, na medida de suas desigualdades e vulnerabilidade, como sujeito coletivo em prol de interesses transindividuais do grupo. Não é a quantidade de mulheres que a torna mais ou menos vulnerável, mas a garantia do exercício de seus direitos e garantias fundamentais asseguram compensações de situações de vulnerabilidade. 
No entanto, a realidade brasileira aponta para falhas na disponibilização das informações sobre resultados de monitoramento de qualidade e potabilidade da água para abastecimento pelas concessionárias de tratamento e de abastecimento, especialmente em nível nacional. Não se encontram ainda incluídos e divulgados os dados de monitoramento da água em nível nacional, não obstante a lei de dados abertos, à luz do Decreto n. 8777/2016 e da Lei 12.527/2011, não estando disponíveis também os estudos de avaliação de toxicidade pela ANVISA/Ministério da Saúde.

A mulher, usualmente provedora de cuidados com a alimentação e sanidade no seio familiar, preocupa-se com a qualidade da água, tanto pela natureza alimentar da água em si como porque dela necessita para produção de alimentos. Sem acesso facilitado a dados sobre a qualidade da água, estar-se-á também facilitando a porta de entrada e a via para doenças, em prejuízo dos cuidados necessários para a melhoria da qualidade da água.

É inegável que a noção de um direito à "água segura" lança as bases para um direito à água potável, ratificando o princípio contemplado no Protocolo Sobre Água e Saúde (Londres, 1999)² que enfatiza um acesso equitativo à água em termos quantitativo e qualitativo, especialmente em relação às pessoas desfavorecidas ou socialmente excluídas (artigo 5으, I).

O direito humano fundamental à água potável e ao saneamento precisa ser galgado e consolidado, em processos decisórios coletivos, com todos os atores, nivelados no poder de compreensão, por empoderamento e sem discriminação.

A Organização das Nações Unidas (ONU), por sua Resolução 64/292, de 28.7.2010 reconheceu o "direito à água potável e ao saneamento como um direito essencial para o pleno aproveitamento da vida e de todos os direitos humanos", tendo sido posteriormente ratificado esse direito por seu Conselho de Direitos Humanos em 2010, no Ato 15/9 e por sua Assembleia Geral, em 2015, no Ato $70 / 169$.

Para atingir os objetivos de desenvolvimento sustentável da Agenda 2030 da ONU em relação à igualdade de gênero (ODS 5) e ao acesso universal a água e saneamento (ODS 6), os participantes da sessão "Mulheres Perspectivas e Desafios", coordenada pelo Women For Water Partnership no 8o Fórum Mundial da Água concordaram ser indispensáveis os seguintes fatores:

- Mudança na mentalidade e reconhecimento quanto à contribuição das mulheres;

- Quota e divisão de papéis, representações igualitárias e integração entre homens e mulheres na gestão;

- Orientação sobre igualdade e equidade;

- Disponibilidade de recursos;

- Treinamento técnico profissional em diferentes níveis para capacitar as mulheres;

- Indicadores e dados desagregados por sexo;

- Envolver todas as partes interessadas, comunidade local, governo e sociedade civil.

Por sua vez, a sessão "Crimes Ambientais, Justiça, Compensação e Violação de Direitos", coordenada e relatada por membros da Comissão Consultiva do Projeto Conexão Água, reuniu e deu voz inclusive a pessoas afetadas por ilícitos ambientais, como a líder indígena Mona Polacca, dos EUA e a marisqueira Janete Sena, do Estado da Bahia, Brasil, visando à identificação de um caminho claro sobre o papel que a sociedade civil pode desempenhar na proteção não apenas das mulheres, mas das comunidades, em defesa de seus direitos, valorizando a justiça socioambiental e melhores práticas em reparação socioambiental. As preocupações de comunidades tradicionais e vítimas de violações de direitos humanos foram objeto dos debates, bem como os desafios enfrentados para ver essas pessoas como líderes, agentes de mudança e parceiros para alcançar o acesso equitativo à água. Aumentar a participação dessas comunidades na gestão e monitoramento da qualidade da água são objetivos a serem alcançados.

Desse painel "Crimes Ambientais, Justiça, Compensação e Violação de Direitos" resultaram algumas sugestões de diretrizes para o desenvolvimento de estratégias e políticas. Passa-se a enumerar

2 Protocolo sobre água e saúde relativo à Convenção de 1992 sobre a proteção e a utilização dos cursos de águas transfronteiriços e de lagos internacionais. 
cada uma das diretrizes propostas e, ao que consta, foram incorporadas pelo 8º Fórum Mundial da Água em seu relatório global:

- Dar direito ao rio e à água os reconhecendo como bem cultural e espiritual da humanidade por meio de decisões judiciais e interpretações doutrinárias.

- Respeitar todas as formas de vida como sagradas. 0 rio e o povo estão ligados intrinsecamente. 0 Rio é fonte de elemento espiritual.

- Incorporação do delito de Ecocídio com o propósito de prevenir e coibir sérios danos ou destruições ao meio ambiente, bem jurídico supraindividual e de valor ou interesse internacional.

- Guerras destroem a ecologia e o direito de viver em condições apropriadas. É preciso promover a cultura da paz junto com a proteção das águas e fazer prevalecer esses direitos.

- São inadmissíveis quaisquer riscos à integridade das águas, sua qualidade, quantidade, seu valor cultural, sagrado e ancestral. Aplica-se para sua proteção e responsabilização o princípio do controle do risco, princípio da precaução, prevenção e a responsabilidade objetiva.

Relatórios e documentos de diversos painéis não apenas do Fórum Alternativo Mundial da Água, como da Vila Cidadã e de sessões do Processo Político, do Processo Cidadão e de Sessão Especial do 8o Fórum Mundial da Água consagraram a natureza de um direito humano fundamental, não se confundindo com mercadoria ou um bem alienável, porque a água, inarredável e intrinsecamente, consubstancia-se na própria vida. Alguns painéis da Sessão Especial e do Processo Cidadão do $8^{\circ}$ Fórum Mundial da Água chegaram à conclusão da natureza jurídica da água como sujeito de direitos, sendo possível, destarte, a responsabilização ambiental por danos extrapatrimoniais pela poluição da água, alargando-se a margem de riscos inaceitáveis 3 .

\section{Conclusões}

Quando se tratam de direitos das mulheres ainda há um vasto espaço a ser conquistado. A equidade de gênero na gestão de recursos hídricos em todo o mundo deve ser considerada uma prioridade, uma vez que haverá mais benefícios ao meio ambiente e mais garantias para as gerações futuras. Essa afirmação se sustenta na compreensão de que mulheres e meninas são mais vulneráveis à falta de água e saneamento, sendo afetadas em relação à saúde e oportunidades de forma desproporcional aos homens, conforme demonstram relatórios do Banco Mundial ${ }^{4}$. Esse dado alarmante foi novamente reconhecido no Painel de Alto Nível sobre a Água, realizado no 8o Fórum Mundial da Água, no qual 12 Chefes de Estado delinearam um plano de ação para alcançar o Objetivo de Desenvolvimento Sustentável 6, consistente em assegurar a disponibilidade e gestão sustentável da água e saneamento para todos 5 .

A valorização da água é um dos eixos de ação, dando importância aos diferentes valores da água para diferentes grupos da sociedade. Contudo, conciliar esses valores diferentes enquanto as demandas continuam aumentando é cada vez mais difícil e as compensações são inevitáveis. Para restaurar o equilíbrio, cada indivíduo deve ser chamado à responsabilidade de valorizar a

\footnotetext{
${ }^{3}$ Conforme relatórios (no prelo) de alguns painéis de sessões do $8^{\circ}$ Fórum Mundial da Água/2018, elaborados com apoio de membros e colaboradores da rede de governança colaborativa do Projeto Conexão Água do MPF apontam nesse sentido, para novas ferramentas jurídicas, tais como planos de segurança da água que pressupõem a transparência das informações qualiquantitativa da água e de seu monitoramento social, que bem se prestem a abarcar o mapeamento e a avaliação de riscos nas Bacias Hidrográficas, com gestão integrada que priorize a efetividade do tratamento do esgoto e a preservação dos mananciais de abastecimento.
}

4 World Development Report 2012. Disponível em: https://siteresources.worldbank.org/INTWDR2012/Resources/ 7778105-1299699968583/7786210-1315936222006/Complete-Report.pdf> Relatório “The Rising Tide, a New Look at Water and Gender", produzido por Maitreyi Bordia Das e Gaia Hatzfeldt para o Banco Mundial. Disponível em <http://documents.worldbank.org/curated/en/901081503580065581/pdf/119074-REVISED-PUBLIC-W17068.pdf>

5 Relatório de painel internacional pede 'mudança fundamental' na gestão da água. Disponível em:

<https://nacoesunidas.org/relatorio-de-painel-internacional-pede-mudanca-fundamental-na-gestao-da-agua/> 
água como fonte de vida e ser um agente de gestão, qualquer que seja a sua esfera de poder ou grau de influência na comunidade.

Por outro lado, os Estados têm o direito e o dever de formular políticas nacionais adequadas para o desenvolvimento, que visem ao constante aprimoramento do bem-estar de toda a população e de todos os indivíduos, com base em sua participação ativa, livre e significativa e no desenvolvimento e na distribuição equitativa dos benefícios daí resultantes 6 . A sociedade precisa decidir com liberdade sobre o que deseja preservar em espaços cidadãos de participação livre, em igualdade de oportunidades e prévio acesso a informações atuais e verossímeis. 0 desenvolvimento sustentável também passa pelo dever do Estado de oferecer condições ao exercício dos direitos humanos e fundamentais e pela obrigação de instituir políticas de promoção desse dever, tendo em conta o direito à participação.

Fomentar a participação, não só das mulheres, mas de todos os usuários de água, entidades da sociedade e órgãos públicos pode contribuir para trazer novas soluções para os problemas hídricos, evitar desperdícios de investimentos, prevenir riscos socioambientais, realizar projetos mais sustentáveis, estabelecer metas de redução da fome, mortalidade infantil e melhorar a igualdade de gênero.

\subsection{Agradecimentos}

Agradecimentos especiais pela participação e contribuição das convidadas palestrantes nos painéis do 8o Fórum Mundial da Água: Raquel Dodge (Procuradora-Geral da República), Christianne Dias (Diretora-Presidente Agência Nacional de Águas), Rosanna Garjuli (Brasil), Asha Abdulrahman (Quênia), Khin Ni Ni Thein (Myanmar), Urutahi Waikerepuru (Nova Zelândia), Arzu Ozyol (Turquia), Alice Bawman-Dentener (representante da Women for Water Partnership), Ivana Farina Navarrete Pena (Secretária de Direitos Humanos e Defesa Coletiva do Gabinete da Presidência do Conselho Nacional do Ministério Público); bem como pelas contribuições de membros da Comissão Consultiva do Projeto Conexão Água, colaboradores do projeto e seus convidados nas diversas atividades de coordenação, keynote speaker, relatoria e moderação em eventos e atividades na semana do 8 WWF, em março de 2018, em Brasilia: Alexandra Facciolli Martins (Promotora de Justiça, MPSP), Anastasya Lavrina (jornalista, Azerbaijão), Carlos Dias (Netherlands);Fernanda Reichardt (pesquisadora CENA/USP, Brasil), Gisela Umbuzeiro, (Professora da Faculdade de Tecnologia, da UNICAMP), Janete Sena (liderança da comunidade marisqueira, BA, Brasil), João Bosco Senra, (Chefe da Assessoria Técnica da Presidência da Companhia de Saneamento de Minas Gerais), Jurandir Siridiwe Xavante (cacique Aldeia Etenhiritipá), Lafayette Sobrinho (Advogado), Lia Vasconcelos Professora da Faculdade de Ciências e Tecnologia da Universidade Nova de Lisboa em Portugal, Lilia Diniz (advogada e mestre pela PROCAM/USP), Malu Ribeiro (SOS-Mata Atlântica e Rede das Águas), Manuel Humberto Cholango Tipanluisa (Ministro-Secretário da Secretaria Nacional de Recursos Hídricos do Equador e dirigente indígena kichwa), Equador Marcelo Drügg Barreto Vianna (professor doutor do curso de MBA de gerenciamento de facilities da POLI/USP, membro de conselhos e instituições), Mariet Verhoef-Cohen (Presidente Women for Water Partnership, Holanda), Marcía Guajajara (liderança indígena Guajajara), Mona Polacca (liderança indígena/EUA), Rawiri Tinirau (Advogado Maori, Nova Zelândia),Satoko Kishimoto (ativista e pesquisadora do Transnational Institute, Holanda) e Solange Teles da Silva (Professora de Direito Ambiental em cursos de pós-graduação da Universidade Mackenzie, Brasil).

\section{Referências}

Brasil (1988). Constituição da República Federativa do Brasil de 1988. Brasília [DF]. Disponível em <http:// www.planalto.gov.br/ccivil_03/constituicao/constituicao.htm> Acesso em 10 jun. 2018.

Conexão Água (n.d.). Manual de Atuação para "Efetivação das Metas de Qualidade das Águas no Brasil: Atuação Estratégica para a Melhoria da Qualidade das Águas. Disponível em <http:// conexaoagua.mpf.mp.br/arquivos/manuais/2018-05-efetivacao-das-metas-de-qualidade-das-aguas-nobrasil.pdf> Acesso em 10 jun.2018.

\footnotetext{
6 Declaração da ONU sobre Direito ao Desenvolvimento de 1986, art. 2º, 3.
} 
Conexão Água (n.d.). Declaração do Ministério Público sobre o Direito à Água. Disponível em <http:// conexaoagua.mpf.mp.br/atuacao-estrategica/eventos/2018/2018-03-17-forum/2018-03-17-declaracaoministerio-publico.pdf> Acesso em 10 jun. 2018.

Organização das Nações Unidas (2015). Agenda 2030 para o Desenvolvimento Sustentável, documento final da agenda pós-2015. Disponível em <https://nacoesunidas.org/wp-content/uploads/2015/10/ agenda2030-pt-br.pdf> Acesso em 10 jun. 2018.

Organização das Nações Unidas (1986). Declaração da ONU sobre Direito ao Desenvolvimento.

Organização das Nações Unidas (n.d.). Resolução da Assembleia Geral da ONU. Resolução A/RES/64/292. Disponível em <www.un.org/ga/search/view_doc.asp?symbol=A/RES/64/292> Acesso em 10 jun. 2018.

Organização das Nações Unidas (n.d.). Resolução da Assembleia Geral da ONU. Resolução A/RES/10/169. Disponível em <http://www.un.org/en/ga/search/view_doc.asp?symbol=A/RES/70/169> Acesso em 10 jun. 2018.

Organização das Nações Unidas (n.d.). Resolução do Conselho dos Direitos Humanos A/HRC/RES/15/9. Disponível em <www.un.org/ga/search/view_doc.asp?symbol=A/HRC/RES/15/9> Acesso em 10 jun. 2018.

Organização das Nações Unidas (n.d.). Relatório de painel internacional pede 'mudança fundamental' na gestão da água. Disponível em: <https://nacoesunidas.org/relatorio-de-painel-internacional-pedemudanca-fundamental-na-gestao-da-agua/> Acesso em 10 jun. 2018.

The World Bank Group (2012). World Development Report 2012. Gender Equality and Development. Disponível em <https://siteresources.worldbank.org/INTWDR2012/Resources/

7778105-1299699968583/7786210-1315936222006/Complete-Report.pdf> Acesso em 10 jun. 2018.

The World Bank Group (n.d.). The Rising Tide, a New Look at Water and Gender. Disponível em <https://openknowledge.worldbank.org/bitstream/handle/10986/27949/W17068.pdf? sequence $=4 \&$ isAllowed $=y>$ Acesso em 10 jun. 2018. 